Tamara Rajić ${ }^{*}$, Isidora Milošević ${ }^{2}$, Ana Rakić ${ }^{3}$

${ }^{1}$ Economics Institute s.c. Belgrade, Serbia

${ }^{2}$ University of Belgrade, Technical Faculty in Bor, Serbia

${ }^{3}$ University of Belgrade, Faculty of Organizational Sciences, Serbia

\title{
The Influential Factors of Health Care Customer Loyalty: Evidence from Serbia
}

DOI: 10.7595/management.fon.2020.0004

Abstract:

Research question: This study aims to investigate the determinants of customer loyalty in a European emerging economy's health care setting. Motivation: In spite of a rising research interest in the determinants of patients' loyalty over previous years, scarce attention has been paid to date to simultaneous examination of the influential factors of patients' loyalty. Although a number of studies have pointed to patients' perceptions of service quality as an important determinant of loyalty, there is a paucity of research of the impact of service quality, at a disaggregate level, on patients' loyalty. Idea: To address this knowledge gap, this study builds upon the South Korean health care service quality measurement instrument and, upon supporting its validity in the Serbian health care setting, examines a relative contribution of service quality dimensions and satisfaction to patients' loyalty. Data: Quantitative research has been performed, by means of a structured questionnaire, on a convenience sample of $\mathbf{3 0 0}$ health care customers in Serbia. Tools: Structural equation modelling (SEM) has been applied to simultaneously examine the impact of service quality dimensions and satisfaction on patients' loyalty. Findings: Results of the study point to patient satisfaction as the most significant determinant of loyalty, followed by tangibles and concern of other medical staff, which in terms of total effect resulted as statistically significant determinants of loyalty. Findings of this study indicate that managerial attention to these predictors may results in higher levels of patients' loyalty to the institution. Contribution: This study adds to the body of knowledge on patients' loyalty and points to the relevance of a more holistic approach in future examinations of customer loyalty in a health care setting.

Keywords: health care service quality, patients' satisfaction, patients' loyalty, structural equation modelling

JEL Classification: M31, C30, I19

\section{Introduction}

A substantial body of literature has emerged over previous three decades on service quality; it has gained the status of the most extensively studied topic in Services Marketing (Choi et al., 2004). A rising interest in service quality has been spurred on by the increase of competitive pressures in service businesses and expected benefits of service quality improvement. A number of studies have supported the antecedent role of service quality to customer satisfaction (Rajaguru, Hassanli, 2018; Ananda \& Sonal, 2019; Zhang et al., 2019). Satisfied customers are praised for higher probability to return to the same company, recommend the company to significant others and spread positive word-of-mouth. Satisfied customers are easier to serve and can be served in a more cost-efficient way (Peer \& Mpinganjira, 2011; Boakye et al., 2017; Cvijovic et al., 2017). Customer satisfaction has also been recognized as the main driver of company's profitability (Milosavljevic et al., 2016). In addition, by spreading positive referrals, satisfied customers lower the costs of attracting new customers (Han \& Hyun, 2015; Almohaimmeed, 2019).

Research on service quality in health care settings indicates that high quality service leads to patient satisfaction and willingness to use services of the same health care provider in the future (Ozturkcan et al., 2009; Kondasani \& Panda, 2015; Boakye et al., 2017; Taqdees et al., 2018; Mahmoud et al., 2019). Provision of high quality service by a health care institution has also been recognized as a means of successful differ- 
entiation among competitors and a source of sustainable competitive advantage leading to improved efficiency, long-term success and organizational sustainability (Ramsaran-Fowdar, 2008; Peer \& Mpinganjira, 2011; Boakye et al., 2017; Giovanis et al., 2018; Taqdees et al., 2018). On the other hand, the delivery of poor health care services leads to patient dissatisfaction, which negatively affects sustainability of health care services (Altuntas et al., 2018).

Whereas health care service quality has been extensively studied in developed economies, the construct remains largely under-studied in Eastern Europe and its emerging economies lag behind other developing economies when it comes to health care service quality examinations. In addition, scarce research attention has been devoted to date to simultaneous examinations of the contribution of health care service quality, at a dimensional level, and customer satisfaction to patients' behavioural intentions. Therefore, this research seeks to contribute to the existing knowledge on patients' loyalty by simultaneous examinations of the contribution of service quality, at a disaggregate level, and satisfaction to patients' loyalty in the context of the Serbian health care system.

A number of health care quality measurement instruments have been proposed to date. This study will build upon Choi et al.'s (2004) health care measurement instrument, which was proposed in the South Korean health care context. The choice of this particular instrument is based on the fact that to date this instrument has been cited 249 times in Scopus database and, according to the best of our knowledge, it is the most influential service quality instrument in the health care context. Taking into consideration that the instrument is developed in one cultural setting and is now being applied in a different context, first, there is a need to examine its validity in the Serbian health care setting. Therefore, this study has two objectives: 1) first, to examine psychometric properties of the aforementioned instrument in the Serbian health care system and second, to simultaneously examine the influence of service quality and satisfaction on patients' loyalty, addressing the construct of service quality at a disaggregate level, i.e., at the level of its constituents.

The remainder of the paper is divided into several sections. The first section deals with the review of literature and proposes a conceptual framework of the study. Methodology of the study is presented within the second section. Results of the study are provided subsequently. Implications stemming from the study's findings are discussed in the following section. The paper ends by noting the limitations of the study and providing directions for future research.

\section{Literature Review}

Historically, medical professionals have been responsible for setting specifications for the provision of quality health care services. However, the traditional way of managing health care quality has been extensively criticized for being overly focused on technical clinical criteria, without taking into account patients' perspective (Peer \& Mpinganjira, 2011). A contemporary health care system calls for putting customers', i.e., patients' interests first. Patient satisfaction is regarded as an important indicator of a nation's health care system quality (Senic \& Marinkovic, 2013). Therefore, there is a need for service quality measurements in health care settings to take into account patients' perceptions of the quality of service provision. Moreover, recent studies have highlighted the importance of measuring both patients' expectations and perceptions of service quality attributes and the examination of relative contribution of quality dimensions to patient satisfaction (Pekkaya et al., 2017; Ali et al., 2018).

It is widely acknowledged that service quality is difficult to measure, due to unique characteristics of services, such as intangibility, heterogeneity, perishability and simultaneity of production and consumption (Boakye et al., 2017). This especially pertains to credence services, which are difficult to evaluate even after provision, and medical services are regarded as a typical representative of credence services. Patients lack necessary knowledge and they are not sufficiently qualified to evaluate the technical aspect of health care service quality (Ramsaran-Fowdar, 2008). Therefore, the North American school of service quality and SERVQUAL scale (Parasuraman et al., 1988) with its orientation towards process aspect of service quality has captured most attention among researchers in the field of service research in general, including health care services.

The SERVQUAL scale implies that service quality should be measured as a difference between customers' perceptions of provided service and their expectations prior to service delivery. As such, the instrument is designed to detect eventual gaps, i.e., areas where service provision fails to meet customers' expectations and to provide the foundation for future improvements in the provision of services. 
Several studies have been performed to examine the applicability of SERVQUAL-based instrument for health care service quality measurement. However, results of the application of SERVQUAL instrument in a health care setting are equivocal. Whereas some previous studies have supported the validity of SERVQUAL instrument for health care service quality measurements in diverse cultural settings (Babakus \& Mangold, 1992; Zarei et al., 2012; Yousapronpaiboon \& Johnson, 2013), it is generally agreed that SERVQUAL scale should be regarded as a good starting point for service quality measurements in a health care context, however, appropriate adaptations of this measurement instrument which would take into account specificities of a health care setting and service delivery are advised (Ramsaran-Fowdar, 2008; Lonial et al., 2010; Al-Neyadi et al., 2016; Kansra \& Jha, 2016; Fan et al., 2017; Mahmoud et al., 2019).

The SERVQUAL scale also provided the base line for Choi et al.'s (2004) study on health care service quality in South Korea. Their study, performed on a sample of outpatients of a general hospital in Seoul, indicated that patients' perceptions on health care service quality depend on the convenience of a healthcare process, concern towards patients expressed by physicians and other medical staff and tangibles. The study further indicated a significant impact of service quality on the perceived value of a medical service and direct influence of both service quality and perceived value on patient satisfaction. Perceived quality, value and satisfaction also emerged as significant direct determinants of patients' loyalty.

Peer and Mpinganjira (2011) applied a modified version of SERVQUAL instrument in South African private medical practice. Their study indicated a significant impact of overall service quality on customer satisfaction and a significant influence of both service quality and satisfaction on patients' behavioural intentions, i.e., willingness to return to the same institution and willingness to recommend the institution, whereas all service quality dimensions, corresponding to SERVQUAL dimensions, emerged as significant predictors of customer satisfaction. According to these authors, customer satisfaction emerged as a more influential determinant of customer behavioural intentions, in comparison with overall service quality. Taking into account the explanatory power of overall service quality on customer satisfaction (which emerged slightly over $50 \%$ ), the authors further concluded that, in addition to service quality, there might be some additional determinants of patient satisfaction which were neglected during the course of the study. However, it should be noted that relationships among the constructs in this study were examined by the application of simple regression analysis.

Ozturkcan et al. (2009) proposed a six-dimensional construct of service quality, comprising tangibility, reliability, responsiveness, assurance, courtesy and empathy, and studied the impact of service quality and satisfaction on patients' loyalty at Marmara University Hospital in Turkey. By the application of multiple regression analysis their study indicated significant impact of all proposed service quality dimensions on patient satisfaction and significant impact of reliability, responsiveness and empathy on patients' loyalty. However, their study did not examine simultaneously the impact of service quality dimensions and satisfaction on patients' loyalty.

In the context of private health care institutions in India, Kondasani and Panda (2015) indicated a six-dimensional construct of service quality, comprising the following dimensions: physical environment, reliability, responsiveness, privacy and safety, customer-friendly staff and communication. By the application of multiple regression analysis the authors found out a significant impact of satisfaction on patients' loyalty, whereas among service quality dimensions physical environment emerged as the most influential determinant of patients' loyalty, followed by customer friendly personnel, communication and responsiveness. According to Trivedi and Jagani's (2018) research, also in the Indian health care setting, service quality dimensions, such as experience with hospital administration, experience with doctors, experience with nursing staff, experience with hospital pharmacy and physical environment, significantly influence patient satisfaction.

Taqdees et al. (2018) examined service quality, patient satisfaction and loyalty in the context of private health care in Pakistan. Their study indicated a five-dimensional construct of service quality, comprising physical environment, customer-friendly environment, communication, privacy and safety and responsiveness. Further examinations, by the application of regression analysis, indicated a significant impact of all quality dimensions on patient satisfaction, whereas with the inclusion of satisfaction as an independent variable in a regression equation the study indicated a statistically significant contribution of two out of five quality dimensions on patients' loyalty, namely, privacy and safety and responsiveness.

Ahmed et al. (2017) studied the construct of service quality, patient satisfaction and loyalty in the Bangladesh health care system. Their study indicated conformity to five SERVQUAL-based dimensions of service quality, revealed differences in the perception of quality dimensions and loyalty among single and married pa- 
tients and among patients belonging to different age groups and indicated a higher level of services provided by private medical institutions, in comparison with public hospitals.

In a recent study in a health care context in Ghana, Boakye et al. (2017) simultaneously examined relatedness among service quality, perceived value, satisfaction and their contribution to patients' loyalty. Results of this study indicated an indirect impact of overall perceptions of health care service quality on patients' loyalty, mediated via satisfaction and perceived value.

Recently, Giovanis et al. (2018) have studied patients' perceptions of service quality in hospital outpatient departments in Greece. Their study has indicated four dimensions of healthcare service quality: medical care, nursing care, administrative services and staff behaviour and the condition of facilities, which contribute to patients' overall quality perceptions. This study also provided evidence of partial mediation of satisfaction in the relationship between overall quality perceptions and patients' intentions. Unlike a majority of previous studies, these authors have simultaneously examined relatedness among health care service quality, satisfaction and patients' behavioural intentions, however, the construct of overall perceptions of service quality has been modelled as an antecedent to satisfaction and patients' future intentions.

Health care services have also occupied the attention of researchers in Serbia. Damnjanovic et al. (2018) studied the determinants of patient satisfaction in Serbia. Findings of their study indicate care of the doctors and support staff as important determinants of patient satisfaction. In an earlier study Filipovic et al. (2010) provided evidence of significant impact of a positive attitude towards public relations and marketing activities of managers of health care institutions on patient satisfaction in Serbia. In another study performed on a sample of Serbian health care customers, Senic and Marinkovic (2013) used a SERVQUAL-based measurement instrument to examine the determinants of student satisfaction with health care services provided by student polyclinics. Their study's findings point to a significant influence of personal relationship with a doctor, promptness of service provision and tangibles on student satisfaction.

Review of literature points to the rising research interest into health care service quality and its effects in developing economies over previous years. It also shows that the majority of previous studies on health care service quality and its consequences have been based upon SERVQUAL measurement instrument. Whereas researchers have agreed on a multidimensional nature of health care service quality, previous studies resulted in different dimensions of health care quality. However, it should be noted that similar traits of service quality construct have been highlighted as important in previous studies: courtesy, knowledge, experience, competence and empathy of doctors and supporting staff, accessibility, atmoshere and physical environment of a health care institution.

However, a vast majority of previous studies have neglected simultaneous examinations of relatedness among quality, satisfaction and loyalty or, as evidenced in a recent study from the context of the Greek healthcare setting (Giovanis et al., 2018), the study took into account patients' overall quality perceptions. Therefore, a disaggregate approach to health care service quality and relative contribution of quality dimensions and satisfaction to patients' loyalty is clearly missing in extant literature and this study aims to provide this missing link to service quality-satisfaction-loyalty relationship. To reach this objective, this study builds upon Choi et al.'s (2004) health care measurement instrument.

Based on the above discussion, and taking into consideration an existing gap in the extant literature, the following hypotheses are proposed:

$\mathrm{H1}$ : Choi et al.'s (2004) health care service quality measurement instrument is a valid and reliable instrument for service quality measurement in the Serbian health care setting;

H2: Health care service quality dimensions have a significant positive effect on patient satisfaction;

H3: Satisfaction has a significant positive effect on patients' loyalty;

H4: Health care service quality dimensions have a significant positive effect on patients' loyalty.

The conceptual model which synthesizes proposed relationships is presented in Figure 1. 




Figure 1: Conceptual model

\section{Methodology}

The study was performed on a convenience sample of health care customers in Serbia. Patients visiting a general practitioner or a specialist physician in one public health care institution in Serbia were invited to participate in the study and the rationale of the study had been explained to them. Data collection was performed by means of structured, self-administered questionnaire and it was anonymous. Data collection took place in a waiting room of the facility. Out of 400 delivered questionnaires, a total of 300 completely fulfilled questionnaires were included in data analysis. Therewith, a requirement related to a sample size of having at least 10 respondents per questionnaire item was satisfied (Boateng et al., 2018).

The measurement instrument used in this study was based on previous research. Items measuring health care service quality and patient satisfaction were taken from Choi et al. (2004). Patients' loyalty to health care service provider was measured using three items adapted from the study of Giovanis et al. (2018). Questionnaire items were measured on a five-point Likert-type response scale, ranging from 1-strongly disagree to 5-strongly agree.

Psychometric properties of the service quality measurement instrument, in the context of the health care system in Serbia, were assessed using exploratory and confirmatory factor analysis. Proposed relationships were examined using structural equation modelling, adhering to Anderson and Gerbing's (1988) two-step approach, which calls for the examination of contructs' validity prior to the investigation of structural relationships. Data analyses were performed using SPSS v.17 and Amos v.16. To estimate statistical significance of indirect relationships the maximum likelihood bootstrapping procedure was performed, using 1000 sub-samples and $95 \%$ bias-corrected confidence intervals.

\section{Results and Discussion}

\subsection{Reliability and validity of the measurement instrument}

Psychometric properties of the measurement instrument, i.e., instrument's reliability and validity, were assessed adhering to Boateng et al.'s (2018) iterative procedure for scale validation in the area of health research. Factor extraction was performed using principal component analysis with varimax rotation. Eigenvalues higher than 1 were chosen as a criterion for factor extraction. Factor loadings lower than 0.40 were suppressed. KMO (Kaiser-Meyer-Olkin) measure of sampling adequacy of 0.934 and statistically significant value of Bartlett's test of sphericity $(x 2=4295.785, \mathrm{df}=153, p<0.01)$ indicated the adequacy of the data for performing a factor analysis. Due to cross-loadings, one item was eliminated from further iterative procedure. The application of exploratory factor analysis resulted in clean four-factor latent structure corre- 
sponding to Choi et al.'s (2004) instrument. The resulting factor model explained $74.393 \%$ of variance in the data. Rotated component matrix is presented in the Appendix.

Confirmatory factor analysis was applied in the following stage. Values of fit indices $(X 2 / d f=1.995, C F I=0.967$, $\mathrm{NFI}=0.936, \mathrm{NNFI}=0.961, \mathrm{RMSEA}=0.058$ ) indicated good fit of the model to the data. The construct reliability was also supported by estimates higher than 0.70. With Cronbach's alpha factors higher than the lower threshold of 0.70 (Hair et al., 2010), resulting dimensions of health care service quality, as well as patients' satisfaction and loyalty, were deemed reliable, i.e., internally consistent, as presented in Table 1.

Table 1: Measurement model results

\begin{tabular}{|c|c|c|c|c|}
\hline $\begin{array}{c}\text { Standardized factor } \\
\text { loadings }\end{array}$ & T-value & AVE & $\begin{array}{l}\text { Construct } \\
\text { reliability }\end{array}$ & $\begin{array}{l}\text { Cronbach's } \\
\text { alpha }\end{array}$ \\
\hline $\begin{array}{c}\text { Doctors' concern } \\
\text { (SQ3) }\end{array}$ & & 0.813 & 0.956 & 0.957 \\
\hline .921 & - & & & \\
\hline .936 & 29.267 & & & \\
\hline .934 & 29.129 & & & \\
\hline .865 & 23.338 & & & \\
\hline .850 & 22.344 & & & \\
\hline $\begin{array}{l}\text { Concern of other } \\
\text { medical staff (SQ2) }\end{array}$ & & 0.684 & 0.916 & 0.919 \\
\hline .775 & - & & & \\
\hline .886 & 16.862 & & & \\
\hline .860 & 16.262 & & & \\
\hline .833 & 15.615 & & & \\
\hline .782 & 14.399 & & & \\
\hline $\begin{array}{l}\text { Convenience of the } \\
\text { medical process (SQ1) }\end{array}$ & & 0.576 & 0.843 & 0.834 \\
\hline .661 & - & & & \\
\hline .683 & 10.267 & & & \\
\hline .851 & 12.172 & & & \\
\hline .824 & 11.921 & & & \\
\hline Tangibles (SQ4) & & 0.463 & 0.774 & 0.792 \\
\hline .656 & - & & & \\
\hline .669 & 9.695 & & & \\
\hline .644 & 9.375 & & & \\
\hline .747 & 10.608 & & & \\
\hline Patient satisfaction & & 0.862 & 0.926 & 0.926 \\
\hline .935 & - & & & \\
\hline .922 & 27.663 & & & \\
\hline Patients' loyalty & & 0.883 & 0.957 & 0.957 \\
\hline .942 & - & & & \\
\hline .926 & 30.907 & & & \\
\hline .950 & 34.154 & & & \\
\hline
\end{tabular}

Validity of a measurement instrument can be explained as "the extent to which an instrument indeed measures the latent dimension or construct it was developed to evaluate" (Boateng et al., 2018; p. 13). Construct validity, which comprises convergent and discriminant validity, was examined for the purpose of this study. Statistically significant factor loadings higher than 0.50 and Average variances extracted (AVEs) per construct above the threshold of 0.50 provided evidence in support of convergent validity (Bagozzi \& Yi, 1991). The only exception, in terms of AVE lower than 0.50 , was tangibility, which will be discussed later on in the text. As none of the $95 \%$ bias-corrected confidence intervals of correlations among the constructs contained unity, evidence was provided in support of discriminant validity (Choi et al., 2004), as presented in Table 2. Bold numbers on the diagonal represent square roots of the AVEs. 
Table 2: Correlations among the constructs, 95\% bias-corrected confidence intervals of correlations and square roots of the AVE values

\begin{tabular}{|c|c|c|c|c|c|c|}
\hline & SQ1 & SQ2 & SQ3 & SQ4 & SAT & LOY \\
\hline SQ1 & 0.759 & & & & & \\
\hline SQ2 & $\begin{array}{c}0.726 \\
(0.638-0.809)\end{array}$ & 0.827 & & & & \\
\hline SQ3 & $\begin{array}{c}0.659 \\
(0.538-0.748) \\
\end{array}$ & $\begin{array}{c}0.717 \\
(0.616-0.792) \\
\end{array}$ & 0.901 & & & \\
\hline SQ4 & $\begin{array}{c}0.575 \\
(0.441-\quad 0.684)\end{array}$ & $\begin{array}{c}0.718 \\
(0.613-0.807)\end{array}$ & $\begin{array}{c}0.565 \\
(0.472-0.669) \\
\end{array}$ & 0.680 & & \\
\hline SAT & $\begin{array}{c}0.625 \\
(0.528-0.709) \\
\end{array}$ & $\begin{array}{c}0.734 \\
(0.651-0.807) \\
\end{array}$ & $\begin{array}{c}0.576 \\
(0.477-0.683) \\
\end{array}$ & $\begin{array}{c}0.810 \\
(0.727-0.889) \\
\end{array}$ & 0.928 & \\
\hline LOY & $\begin{array}{c}0.625 \\
(0.539-0.701)\end{array}$ & $\begin{array}{c}0.713 \\
(0.631-0.774)\end{array}$ & $\begin{array}{c}0.592 \\
(0.485-0.673)\end{array}$ & $\begin{array}{c}0.850 \\
(0.772-0.909)\end{array}$ & $\begin{array}{c}0.912 \\
(0.863- \\
0.945)\end{array}$ & 0.939 \\
\hline
\end{tabular}

Note: SQ1-service quality dimension 1, SQ -service quality dimension 2, SQ3-service quality dimension 3, SQ4-service quality dimension 4, SAT-patient satisfaction, LOY-patients' loyalty

Reliability and construct validity which were indicated by this study's findings provided support to hypothesis $\mathrm{H} 1$. Therefore, it can be concluded that the health care service quality measurement instrument which was proposed by Choi et al. (2004) can also be regarded as a valid measurement instrument in the Serbian health care context.

\subsection{Structural analysis}

Excellent overall fit of the model to the data resulted from structural analysis $\left(X^{2}=1.995, C F I=0.967\right.$, $\mathrm{NFI}=0.936, \mathrm{NNFI}=0.961$, RMSEA $=0.058$ ). Hypotheses $\mathrm{H} 2, \mathrm{H} 3$ and $\mathrm{H} 4$ were examined by calculating standardized direct effects. Results of structural analysis are presented in Table 3.

Table 3: Standardized direct effects

\begin{tabular}{|l|c|c|c|}
\hline \multicolumn{1}{|c|}{ Hypothesis } & $\begin{array}{c}\text { Standardized } \\
\text { estimates }\end{array}$ & t-values & $\begin{array}{c}\text { Results of } \\
\text { hypothesis testing }\end{array}$ \\
\hline H2.1: Convenience $\rightarrow$ Patient satisfaction & .128 & 1.742 & Not supported \\
\hline $\begin{array}{l}\text { H2.2: Concern of other medical staff } \rightarrow \\
\text { Patient satisfaction }\end{array}$ & .229 & 2.442 & Supported \\
\hline $\begin{array}{l}\text { H2.3: Doctors' concern } \rightarrow \text { Patient } \\
\text { satisfaction }\end{array}$ & .007 & .111 & Not supported \\
\hline H2.4: Tangibles $\rightarrow$ Patient satisfaction & .568 & 6.327 & Supported \\
\hline H3: Patients satisfaction $\rightarrow$ Loyalty & .629 & 8.752 & Supported \\
\hline H4.1: Convenience $\rightarrow$ Patients' loyalty & .053 & 1.016 & Not supported \\
\hline $\begin{array}{l}\text { H4.2: Concern of other medical staff } \rightarrow \\
\text { Patients' loyalty }\end{array}$ & -.055 & -.842 & Not supported \\
\hline H4.3: Doctors' concern $\rightarrow$ Patients' loyalty & .053 & 1.148 & Not supported \\
\hline H4.4: Tangibles $\rightarrow$ Patients' loyalty & .320 & 3.977 & Supported \\
\hline
\end{tabular}

The findings of this study, which indicate satisfaction as the most significant direct determinant of patients' loyalty, provide support for hypothesis H3. A significant direct impact of satisfaction on patients' loyalty has been also supported in previous studies (Choi et al., 2004; Giovanis et al., 2018). Hypotheses H2 and H4 are only partially supported, as among service quality dimensions concern of other medical staff and tangibles emerged as statistically significant direct determinants of patient satisfaction, whereas, among service quality dimensions, tangibles is the only dimension which emerged as statistically significant direct predictor of patients' loyalty. A significant impact of tangibles on patient satisfaction has also been supported in previous research on the determinants of health care customer satisfaction in the Serbian health care setting (Senic \& Marinkovic, 2013). 
By the application of bootstrapping procedure with 1000 sub-samples and $95 \%$ bias-corrected confidence intervals, in terms of total effects on loyalty, two service quality dimensions, tangibles $(\gamma=0.359, p<0.05)$ and concern of other medical staff $(\gamma=0.144, p<0.05)$, emerged as statistically significant predictors. However, findings of this study do not imply that other quality dimensions are not significant predictors of patients' loyalty. It is possible that an important mediating variable exists between quality dimensions and loyalty, which has not been included in this study. According to Choi et al. (2004), there are other cognitive constructs besides patient satisfaction and service quality, such as perceived value, which influence patients' loyalty and which may mediate the impact of service quality dimensions on patients' loyalty. As other constructs have not been considered in this study, this is one of its limitations.

Conclusion

\subsection{Implications of the study}

The objective of this study was twofold. First, to examine the applicability of Choi et al.'s (2004) service quality measurement instrument in the Serbian health care setting and second, to simultaneously investigate a relative impact of service quality, at the disaggregate level, and satisfaction on patients' loyalty. By indicating a relative importance of loyalty determinants this study was intended to contribute to the current body of knowledge on health care customer loyalty.

This study's findings provide valuable insights into health care institutions' management. Results of the study indicate that by the improvement of other medical staff concern towards patients and tangible aspects of service quality health care institutions can positively contribute to patient satisfaction, which, in addition to tangibles, directly contributes to patients' loyalty. Findings of this study indicate that both quality and satisfaction of patients should be regarded as strategic tools by decision-makers in health care institutions. This especially pertains to privately owned medical institutions, as in private practice customers vote with their money for those institutions which provide a high level of service. Therefore, both quality and satisfaction should be continuously monitored and measured, especially taking into account the potential of big data analytics in a health care sector (Jovanovic Milenkovic et al., 2019), and a possibility to provide high quality health care services.

An interesting finding stemming from this study is the insignificant effect of doctors' concern on patients' loyalty. However, one should not come to the conclusion that doctors' concern is irrelevant from patients' perspective. There may be some other variables which mediate the impact of doctors' concern on patients' loyalty. This assumption, however, merits further investigation.

\subsection{Limitations and future research directions}

This study is not without limitations and their discussion should be in order. The major limitation of the study is that it was based on a convenience sample of health care customers, recruited from only one public health care institution. Another limitation of this research relates to cross-sectional nature of the data, which allows only for correlational inferences to be made. Therefore, this study's findings should not be generalized to the entire Serbian health care setting. It may be worthwhile to perform future research on a more representative sample of the Serbian health care customers.

Confirmatory analysis resulted in the AVE value of tangibles dimension which was lower than the threshold of 0.50 , therewith affecting discriminant validity of this quality dimension. This situation may indicate that some facets of tangibility, which are important from the perspective of health care customers, have not been properly addressed by this study.

As examinations of service quality perceptions depend on the type and variety of services offered by a health care institution, and the length of interaction between patients and medical staff, i.e., on whether it is a daily visit to an institution or a longer and more complex stay at a medical facility, these differences should be taken into account in a proposal of managerially relevant measurement instrument.

As indicated by Ramsaran-Fowdar's (2008) study findings, expectations drive patients' evaluations of service quality in a health care setting. Consequently, to determine possible negative gaps in patients' evaluation of health care services, the authors of this study would advise managers of health care institutions to periodically measure both patients' perceptions and their expectations. In case of negative gaps between patients' perceptions and expectations, this approach would allow for timely actions to be undertaken and point to proper allocation of resources for service quality improvement.

Taking into account Boakye et al.'s (2017) findings of the importance of high value for money for patients' behavioural intentions, future research would also benefit from an examination of a more holistic model of patients' loyalty. 


\section{REFERENCES}

[1] Ahmed, S., Tarique, K. Md., \& Arif, I. (2017). Service quality, patient satisfaction and loyalty in the Bangladesh healthcare sector. International Journal of Health Care Quality Assurance, 30(5), 477-488. DOI 10.1108/IJHCQA-01-2017-0004

[2] Al-Neyadi, H. S., Abdallah, S., \& Malik, M. (2016). Measuring patient's satisfaction of healthcare services in the UAE hospitals: Using SERVQUAL. International Journal of Healthcare Management, 11(2), 96-105. DOI:10.1080/20479700.2016.1266804

[3] Ali, S. S., Basu, A., \& Ware, N. (2018). Quality measurement of Indian commercial hospitals - using a SERVQUAL framework. Benchmarking: An International Journal, 25(3), 815-837. DOI:10.1108/bij-05-20160060

[4] Almohaimmeed, B. (2019). Pillars of customer retention: An empirical study on the influence of customer satisfaction, customer loyalty, customer profitability on customer retention. Serbian Journal of Management, 14 (2), 421 - 435. DOI:10.5937/sjm14-15517

[5] Altuntas, S., Dereli, T., \& Kaya, Ý. (2018). Monitoring patient dissatisfaction: a methodology based on SERVQUAL scale and statistical process control charts. Total Quality Management \& Business Excellence, 1-31. DOI:10.1080/14783363.2018.1457434

[6] Ananda, S., \& Sonal, D. (2019). Service quality dimensions and customer satisfaction: empirical evidence from retail banking sector in Oman. Total Quality Management \& Business Excellence, 30(15/16), 16161629. DOI: $10.1080 / 14783363.2017 .1393330$

[7] Anderson, J. C., \& Gerbing, D. W. (1988). Structural equation modeling in practice: A review and recommended two-step approach. Psychological Bulletin, 103(3), 411-423. DOI:10.1037/0033-2909.103.3.411

[8] Babakus, E., \& Mangold, G.W. (1992). Adapting the SERVQUAL Scale to Hospital Services: An Empirical Investigation. Health Services Research, 26(6), 767-786.

[9] Bagozzi, R .P., \& Yi, Y. (1991). Mutitrait-multimethod matrices in consumer research. Journal of Consumer Research, 17, 426-439, DOI: 10.1086/208568

[10] Boakye, K. G., Blankson, C., Prybutok, V. R., \& Qin, H. (2017). An assessment of national healthcare service delivery: a Ghanaian illustration. International Journal of Quality \& Reliability Management, 34(5), 649666. DOI 10.1108/IJQRM-12-2014-0200

[11] Boateng, G. O., Neilands, T. B., Frongillo, E. A., Melgar-Quiñonez, H. R., \& Young, S. L. (2018). Best Practices for Developing and Validating Scales for Health, Social, and Behavioral Research: A Primer. Frontiers in Public Health, 6, 1-18, DOI:10.3389/fpubh.2018.00149

[12] Choi, K., Cho, W., Lee, S., Lee, H., \& Kim, C. (2004). The relationships among quality, value, satisfaction and behavioral intention in health care provider choice: A South Korean study. Journal of Business Research, 57, 913-921. DOI:10.1016/S0148-2963(02)00293-X

[13] Cvijovic, J., Kostic-Stankovic, M., \& Reljic, M. (2017). Customer relationship management in banking industry: Modern approach. Industrija, 45(3), 151-165. DOI:10.5937/industrija45-15975

[14] Damnjanovic, V., Janicic, R., \& Jovanovic, V. (2018). Factors affecting patient satisfaction in the health care sector in Serbia. Srpski Arhiv za Celokupno Lekarstvo, 146(9-10), 506-511, DOI: https://doi.org/10.2298/SARH170718195D

[15] Fan, L., Gao, L., Liu, X., Zhao, S., Mu, H., Li, Z., Shi, L., Wang, L., Jia. X., Ha, M., \& Lou, F. (2017). Patients' perceptions of service quality in China: An investigation using the SERVQUAL model. PLOS ONE, 12(12), e0190123. DOI:10.1371/journal.pone.0190123

[16] Filipovic, V., Cicvaric, S., Stavljanin, V., Damnjanovic, V., Radojicic, Z., Zarkic Joksimovic, N., \& Gogic, A. (2010). Influence of healthcare institution managers' proactive approach to communication activities on patient satisfaction. Vojnosanitetski pregled, 67(4), 267-271. DOI: 10.2298/VSP1004267F

[17] Giovanis, A., Pierrakos, G., Rizomyliotis, I., \& Binioris, S. (2018). Assessing service quality and customer behavioral responses in hospital outpatient services: A formative measurement approach. International Journal of Quality and Service Sciences, 10(2), 98-116. DOI 10.1108/IJQSS-03-2017-0023

[18] Hair, J.F., Anderson, R.E., Tatham, R.L. and Black, W. C. (2010). Multivariate Data Analysis: A Global Perspective (7th Edition). Pearson Prentice Hall, New Jersey.

[19] Han, H., \& Hyun, S. S. (2015). Customer retention in the medical tourism industry: Impact of quality, satisfaction, trust, and price reasonableness. Tourism Management, 46, 20-29. DOI:10.1016/j.tourman.2014.06.003

[20] Jovanovic Milenkovic, M., Vukmirovic, A., \& Milenkovic, D. (2019). Big data analytics in the health sector: challenges and potentials. Management: Journal of Sustainable Business and Management Solutions in Emerging Economies, 24(1), 23-30. DOI: 10.7595/management.fon.2019.0001

[21] Kansra, P., \& Jha, A. K. (2016). Measuring service quality in Indian hospitals: an analysis of SERVQUAL model. International Journal of Services and Operations Management, 24(1), 1-17. DOI:10.1504/ijsom.2016.075761

[22] Kondasani, R. K. R., \& Panda, R. K. (2015). Customer perceived service quality, satisfaction and loyalty in Indian private healthcare. International Journal of Health Care Quality Assurance, 28(5), 452-467. DOI 10.1108/IJHCQA-01-2015-0008 
[23] Lonial, S., Menezes, D., Tarim, M., Tatoglu, E., \& Zaim, S. (2010). An evaluation of SERVQUAL and patient loyalty in an emerging country context. Total Quality Management \& Business Excellence, 21(8), 813-827. DOI:10.1080/14783363.2010.487663

[24] Mahmoud, A. B., Ekwere, T., Fuxman, L., \& Meero, A. A. (2019). Assessing Patients' Perception of Health Care Service Quality Offered by COHSASA-Accredited Hospitals in Nigeria. SAGE Open, (April-June), 19. DOI: $10.1177 / 2158244019852480$

[25] Milosavljevic, M., Milanovic, N., \& Benkovic, S. (2016). Antecedents of Hotel Profitability: Empirical Evidence from Belgrade. Management: Journal for Theory and Practice Management, 21(81), 77-85. DOI: 10.7595/management.fon.2016.0031

[26] Ozturkcan, S., Aydin, S., Ates, M., \& Cetin, T. A. (2009, March). Effects of Service Quality on Customer Satisfaction and Customer Loyalty: Example of Marmara University Hospital. Paper presented at the International Congress on Performance and Quality in Health, in Antalya, Turkey. Available at https://ssrn.com/abstract=1362601, http://dx.doi.org/10.2139/ssrn.1362601

[27] Parasuraman, A., Zeithaml, V. A., \& Berry, L. L. (1988). SERVQUAL: A multiple-item scale for measuring consumer perceptions of service quality. Journal of Retailing, 64(1), 12-40.

[28] Peer, M., \& Mpinganjira, M. (2011). Understanding service quality and patient satisfaction in private medical practice: A case study. African Journal of Business Management, 5(9), 3690-3698, DOI: 10.5897/AJBM10.1559

[29] Pekkaya, M., Pulat Ýmamoðlu, Ö., \& Koca, H. (2017). Evaluation of healthcare service quality via Servqual scale: An application on a hospital. International Journal of Healthcare Management, 1-8. DOI:10.1080/20479700.2017.1389474

[30] Rajaguru, R., \& Hassanli, N. (2018). The role of trip purpose and hotel star rating on guests' satisfaction and WOM. International Journal of Contemporary Hospitality Management, 30(5), 2268-2286; DOI: 10.1108/IJCHM-01-2017-0044

[31] Ramsaran-Fowdar, R. R. (2008). The relative importance of service dimensions in a healthcare setting. International Journal of Health Care Quality Assurance, 21(1), 104-124. DOI 10.1108/09526860810841192

[32] Senic, V., \& Marinkovic, V. (2013). Patient care, satisfaction and service quality in health care. International Journal of Consumer Studies, 37(3), 312-319. DOI:10.1111/j.1470-6431.2012.01132.x

[33] Taqdees, F., Shahab, A. M., \& Asma, S. (2018). Hospital healthcare service quality, patient satisfaction and loyalty: An investigation in context of private healthcare systems. International Journal of Quality \& Reliability Management, 35(6), 1195-1214. DOI 10.1108/IJQRM-02-2017-0031

[34] Trivedi, R., \& Jagani, K. (2018). Perceived service quality, repeat use of healthcare services and inpatient satisfaction in emerging economy: Empirical evidences from India. International Journal of Pharmaceutical and Healthcare Marketing, 12(3), 288-306. DOI 10.1108/IJPHM-11-2017-0065

[35] Yousapronpaiboon, K. C., \& Johnson, W. (2013). Measuring hospital out-patient service DOI:10.1108/LHS07-2012-0023

[36] Zarei, A., Arab, M., Froushani, A. R., Rashidian, A., \& Tabatabaei, M. G. (2012). Service quality of private hospitals: The Iranian Patients' perspective. BMC Health Services Research, 12(31), 1-7. DOI:10.1186/1472-6963-12-31

[37] Zhang, M., He, X., Qin, F., Fu, W., \& He, Z. (2019). Service quality measurement for omni-channel retail: scale development and validation. Total Quality Management \& Business Excellence, 30(sup1), S210S226. DOI: 10.1080/14783363.2019.1665846

Received: 2020-01-27

Revision requested: 2020-04-06

Revised: 2019-04-09 (1 revision)

Accepted: 2020-04-10

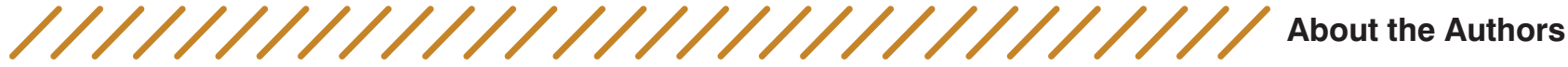

\section{Tamara Rajić \\ Economics Institute s.c. Belgrade, Serbia e-mail: tamara.rajic@ecinst.org.rs}

Tamara Rajic is a research associate at the Economics Institute s.c. Belgrade. She holds a doctoral degree from the Faculty of Organizational Sciences, University of Belgrade.

Her main research interests are consumer behaviour and multivariate data analysis across service industries. She co-authored a number of research papers which have been published in national and international journals.

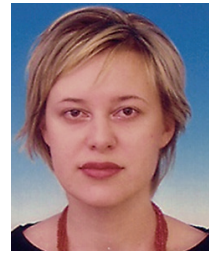


Isidora Milošević

University of Belgrade, Technical faculty in Bor, Serbia e-mail:imilosevic@tfbor.bg.ac.rs

Isidora Milosevic is an Associate Professor at the Technical faculty in Bor. Her main research interests revolve around structural equation modelling, strategic management, corporate social responsibility and marketing in small and medium-sized entreprises.

She co-authored a number of research papers published in international scientific journals and has led several international research projects.

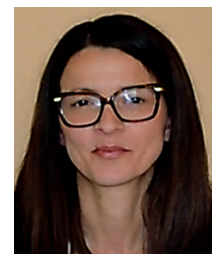

Ana Rakić

University of Belgrade, Faculty of Organizational Sciences, Serbia e-mail: ana.rakic@fon.bg.ac.rs

Ana Rakić is an Assistant Professor at the University of Belgrade, Faculty of Organizational Sciences. Her main research interests are standardisation, metrology, accreditation, certification, engineering communications and logistics. She is a coauthor of many papers in international and national journals and conferences and a member of four commissions at the National Institute for Standardization of Serbia.

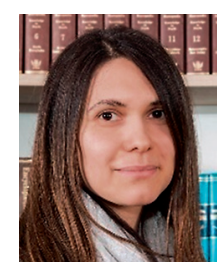

\section{Appendix}

Rotated component matrix

\begin{tabular}{|c|c|c|c|c|}
\hline & \multicolumn{4}{|c|}{ Component } \\
\hline & 1 & 2 & 3 & 4 \\
\hline \multicolumn{5}{|l|}{ Doctors' concern (SQ3) } \\
\hline The doctor let me ask many questions regarding my condition & .879 & & & \\
\hline $\begin{array}{l}\text { The doctor paid enough attention to my concerns regarding } \\
\text { the medical procedure }\end{array}$ & .849 & & & \\
\hline The doctor made me feel comfortable & .834 & & & \\
\hline The doctor adequately explained my condition & .803 & & & \\
\hline The doctor was polite & .781 & & & \\
\hline \multicolumn{5}{|l|}{ Concern of other medical staff (SQ2) } \\
\hline The nurses adequately explained the medication procedure & & .813 & & \\
\hline The nurses were friendly & & .787 & & \\
\hline The nurses tried to help me as much as possible & & .771 & & \\
\hline The nurses showed concern for me & & .730 & & \\
\hline There was a good coordination among medical staff & & .575 & & \\
\hline \multicolumn{5}{|l|}{ Convenience of the medical process (SQ1) } \\
\hline Laboratory tests were done promptly & & & .798 & \\
\hline The procedure to get to laboratory testing was convenient & & & .783 & \\
\hline The payment procedure was quick and simple & & & .724 & \\
\hline $\begin{array}{l}\text { The process of setting up an appointment with the doctor was } \\
\text { easy and simple }\end{array}$ & & & .603 & \\
\hline \multicolumn{5}{|l|}{ Tangibles (SQ4) } \\
\hline $\begin{array}{l}\text { It was easy to use amenities at the hospital (coffee machine, } \\
\text { public telephone,...) }\end{array}$ & & & & .829 \\
\hline The hospital is well equipped & & & & .829 \\
\hline The waiting rooms for doctors look pleasant & & & & .705 \\
\hline $\begin{array}{l}\text { It was easy to find necessary facilities (laboratory, } \\
\text { doctor's office, etc.) }\end{array}$ & & & & .495 \\
\hline Eigenvalues & 4.270 & 3.585 & 2.913 & 2.623 \\
\hline$\%$ of Variance & 23.721 & 19.919 & 16.182 & 14.571 \\
\hline Cumulative \% & 23.721 & 43.639 & 59.822 & 74.393 \\
\hline
\end{tabular}

